by this method, whereas, using our method, we were able to detect chlorine in mixtures of $0.5 \mathrm{cc}$. N/I00 sodium chloride with 20 cc. of $\mathrm{N} / 5$ potassium bromide and iodide. In fact, the results of all our qualitative experiments indicate that absolutely no loss of chlorine is suffered in liberating and expelling the iodine and bromine.

To test the adequacy of the above directions we have had first-and second-year students of the University of Cincinnati analyze some forty mixtures of chlorides, bromides, iodides and sulphocyanates. The solutions were of fifth-normal to normal strength. In the reports there was but a single error, one student reporting chlorine when none was present. Some twenty-five mixtures of more dilute solutions, some containing as low as $0.5 \mathrm{cc}$. of the $\mathrm{N} / \mathrm{I} 00$ solution of one or other of the halide salts, many containing sulphocyanate and some containing salts of other acids, including reducing agents, such as sulphites, ferrocyanides, oxalates, etc., were analyzed by more experienced persons without error.

Bugarszky' has employed potassium biiodate and dilute sulphuric acid for the quantitative separation of bromine and chlorine but has not attempted to separate iodine from the other halogen elements. We hope soon to be able to communicate a method for the estimation of all three elements.

\title{
THE TESTING OF COAL TAR AND OILS AND AN IM- PROVED TESTING STILL.
}

BY H. W. JAYNE.

Received June 4, 1903.

In the examination of coal tars and oils, and in determining the per cent. of water they contain, it is necessary to distil a considerable quantity of material, from 500 to $1000 \mathrm{cc}$. at least. In treatises on this subject, it is usual to recommend the use of glass retorts of several liters capacity. As the temperature in making a complete test often rises to $400^{\circ} \mathrm{C}$., and as water is usually present, the risk of breakage is very great; and when the distillation is finished, it is impossible to remove the pitch or residue completely.

In our laboratory, where hundreds of these tests are made every

1 Ztsckr, anorg. Chem, 10, 387 (1895). 
year, we found it necessary to substitute a metal still, and, in the course of time, improvements have been suggested by the different chemists making these tests, until a form of still and condenser has been adopted, which will be found convenient for those engaged in this line of work.

The still is of heavy copper with straight sides so that it can be easily and thoroughly cleaned. The upper edge is surrounded

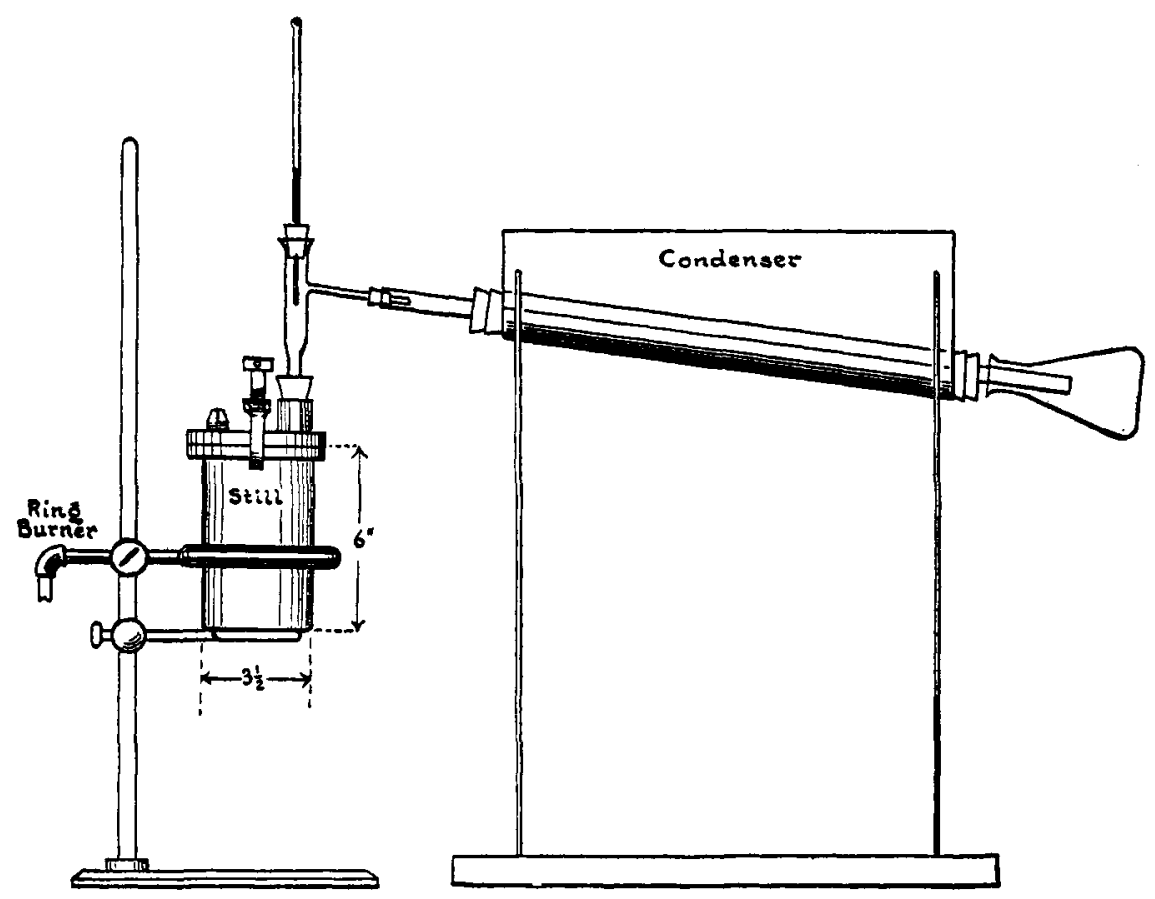

with a heavy turned ring. The lid is of brass, and is clamped to the still by a single clamp passing over the top, a paper gasket being placed between the two metal surfaces. The condenser consists of a copper trough open at the top, through which passes a glass tube 24 inches long. This form of condenser is particularly advantageous for tar distillations. It is filled with water at the beginning of the test, and this is sufficient to condense all the lighter portions. When the fractions containing naphthalene begin to distil, they are liable to choke the tube by the crystallizing of this body. To prevent this, a burner is placed under the trough 
and the water warmed to any degree required. When still higher temperatures are reached, where water cannot be used owing to danger of cracking the tube, it can readily be drawn off by the small cock.

In cases where it is necessary to distil very volatile liquids, pieces of ice or a freezing-mixture may be placed in the trough.

For oil-testing, the long Liebig condenser is not advantageous: it is difficult to clean; and on account of its length, considerable material adheres to the sides. As all tests of oils, naphthas and benzenes are run slowly, so that the distillate flows from the condenser in single drops, a long tube and flowing water is unnecessary.

One filling of water will suffice for many tests of benzenes or oils. If, however, flowing water is needed, the condenser is fitted with connections for tubing.

For water determinations, a small still is used of a capacity of I000 cc. sufficient for distilling $500 \mathrm{cc}$. of tar. For complete tests of tars, especially if the light oils are to be examined, $1000 \mathrm{cc}$. should be used, and the still has a total capacity of $2000 \mathrm{cc}$.

For water determinations, great care must be taken in collecting the sample. If the shipment is made in bulk, a small cock should be placed in the pipe line from the car or boat to the tanks, and a small stream allowed to flow during the entire pumping. The quantity so collected should be violently stirred, and at once filled into wide-mouthed quart bottles or cans before any separation can take place. $500 \mathrm{cc}$. of this sample are filled into the still, the lid securely clamped, and the tube and thermometer put in place. If heat is applied to the bottom of the still, great care must be used, as the contents will readily foam and boil over, if much water is present; this is especially true of tars containing much free carbon along with water, and also of certain oil tars in which the water forms an emulsion.

To avoid this, a ring burner is provided which surrounds the still, and is at first placed so that the heat strikes about the top of the tar in the still. Little attention need be given the distillation but from time to time the ring burner is lowered, until finally nearly all the water is driven out, when, if necessary, an additional burner is placed under the bottom. 
In order to be certain that all water is expelled, the temperature of the thermometer in the vapor should reach $200^{\circ} \mathrm{C}$. As the distillation proceeds, oil comes over with the water until at $200^{\circ}$ a considerable quantity of the former has distilled. The volume of the water is then read off in cubic centimeters, and gives the volume per cent., on which all these tests are based.

If, after the water has been determined, it is desired to examine the tar or oil further, the oil which has distilled over with the water is carefully separated from the latter and added to the cooled tar in the still, and the distillation recommenced; thus, the subsequent determination will be based on dry tar. Unless this is done, false results are obtained, due to the oils distilling at lower temperatures in the presence of vapor of water. For example, a tar, which, if dry, would show 5 per cent. distilling under $200^{\circ}$ C., might show 20 per cent. to the same point if much water was present.

The ring burner may be dispensed with during this latter distillation, and it is advisable to cover the still with a sheet of asbestos, if a high temperature is to be finally reached.

If at any time it is desired to examine the material in the still, this can be done without dismounting the apparatus by removing the small plug in the lid, and introducing a rod. The pitch or residue can be tested as to the melting-point or other properties, and if not of the desired test, the distillation can be continued.

Some tars are exceedingly difficult to free from water, the contents of the still boiling over notwithstanding all precautions. If it is desired to determine only the water in these, the removal of the latter can be greatly facilitated by adding to the tar a hydrocarbon, boiling slightly higher than water-crude or refined toluene, for instance. This thins the tar, and as it distils readily, carries over the water completely. Distillations which otherwise would require hours to complete, can be then readily made in twenty minutes.

This method is also very advantageous for determining water in naphthalene or oils rich in this substance, as it facilitates the driving out of the last traces of water, and prevents crystallizing of the naphthalene in the condenser tube and receiver, and permits the volume of water to be readily read off. 
In these determinations a pure product need not be used-any hydrocarbon boiling tetween $100^{\circ}$ and $200^{\circ}$ will serve, the precaution being taken, however, to determine how much water it contains, and allowing for the same.

Recently a German patent No. I30,295 was granted for determining water in substances by adding a higher boiling liquid thar: water and one that does not mix with it. It is to be regretted that these simple laboratory methods should be made the subjects of patents, and it is difficult to understand the object of taking such a patent; but in this case it would be invalid in the United States, as the method has been used for a long time at different works.

LABORATORY, BARRETT MANUFACT'RING Co.

\section{A PROCESS FOR MAKING AVAILABLE PHOSPHATES.}

BY C. H, DEMPWOLF, JR,

Received May 29, 1903.

A NUMBER of processes for the manufacture of available phosphates by means other than that of sulphuric acid have been recently proposed. From among these processes the following have been taken as seeming of the most importance.

G. F. Wilson ( $186 \mathrm{I}$ ) patented a process, which consists in treating ground mineral phosphates, bone-black, etc., with fused sodium bisulphate and steam under high pressure. A double decomposition of the tricalcium phosphate into calcium sulphate and sodium phosphate is claimed for the process, thus leaving the phosphoric acid in a form more available as a plant food. The source of the bisulphate is the waste product obtained in the manufacture of sulphuric and hydrochloric acids. ${ }^{1}$

G. A. Liebig ( 1881 ) proposed a process in which phosphates are mixed with carbon and subjected to a high heat. The proportions given are two parts of the phosphate to one of carbon. ${ }^{2}$

The process of Brunner and Zanner consists in treating the finely powdered natural phosphates with a solution of sodium bisulphate. After filtration, the liquid contains the calcium acid phosphate, which is then precipitated by an excess of lime. ${ }^{3}$

1 U. S. Patent 75,325 .

2 U. S. Patent $24 I, 868$.

3 Moniteur Srientifique, 1892, p. 100, and Eng. Patent 2,389, Feb. 8, 1892 . 